\title{
Improvement to Foot and Skin Appearance by Using Copper Oxide Impregnated Socks - A Report of a Large Scale Internet Based User Survey
}

Gadi Borkow ${ }^{\star}$, Vikram Kanmukhla and Alastair B Monk

Cupron Inc, 800 East Leigh Street, Suite 123, Richmond VA, USA

*Corresponding author: Gadi Borkow, Cupron Inc. Hameyasdim 44, Gibton 76910, Israel, Tel: 972-546-611287; E-mail: gadi@cupron.com

Received date: December 28, 2016; Accepted date: January 11, 2017; Published date: January 20, 2017

Copyright: ( 2017 Borkow G, et al. This is an open-access article distributed under the terms of the Creative Commons Attribution License, which permits unrestricted use, distribution, and reproduction in any medium, provided the original author and source are credited.

\begin{abstract}
Copper has two key properties that make it an attractive component to introduce into textiles and socks in particular - it has potent biocidal properties and is an essential trace element vital for the normal function of skin. The capacity of copper oxide impregnated socks to kill fungi that causes tinea pedis (athlete's foot) and to enhance skin elasticity has already been demonstrated.

In the current study, we assessed the beneficial effect on the skin of the foot in the wider population by supplying socks impregnated with microscopic copper oxide particles to 5,000 individuals that were identified via an internet survey as people who had experienced athlete's foot within the past 6 months or were concerned about the appearance of their feet. Each individual received 3 complementary pairs of socks and was asked to use them as they would normally use their own socks. After 90 days 3,603 paricipants answered an online questionnaire. The vast majority $(82 \%)$ of responders that felt uncomfortable showing their bare feet in public before using the socks reported a meaningful improvement to their foot skin following the use of the socks for at least 5 hours a day. $61 \%$ of respondents reported elimination or reduction of their foot odor, and $60 \%$ reported stopping using a foot care regime or therapy due to using the supplied socks. $51 \%$ indicated that the socks improved the appearance of their feet and $58 \%$ indicated they were now more comfortable showing their feet in public.
\end{abstract}

In view of the above, it can be concluded that the simple use of copper oxide impregnated socks for at least 5 hours a day helps improve the foot skin well-being and overall appearance of the skin.

Keywords: Copper oxide; Socks; Tinea pedis; Odor; Internet survey

\section{Introduction}

Copper is one of the essential trace minerals needed for the ordinary function of most tissues in our body [1]. In the skin, copper serves as a cofactor of many enzymes and polysaccharides, such as metalloproteinases, lysyl oxidase, glycosaminoglycans and small proteoglycans. These factors are needed for cell proliferation, epithelization, production and secretion of collagen, elastin, integrins and fibrinogen, protection against free radicals and extracellular matrix protein cross-linking stabilization [2-9]. The absorption of copper ions through skin has previously been demonstrated $[10,11]$.

Copper also has intrinsic potent wide spectrum biocidal properties $[12,13]$. Copper was used throughout human history by many geographically separated civilizations to treat skin pathologies [14]. It is for the biocidal properties of copper that copper and copper-based compounds are widely used today in many consumer applications [15-19]. In medicine, copper is used mainly for preventing contraception in intrauterine devices [20].

More recently, a platform technology has been developed by which copper oxide particles are permanently embedded in polymeric matrixes used in the production of fibers and yarns [21,22]. Textile products, made with these fibers and yarns are cosmetotextiles that in contact with the skin have a positive effect [23]. For example, pillowcases containing microscopic copper oxide particles have been shown in several double blind placebo controlled trials to reduce wrinkles and fine lines and improve the well-being of the skin [24-26].

Tinea pedis (also referred to as athlete's foot) is a contagious fungal foot infection estimated to affect $\sim 15 \%$ of the general population, and even affect higher proportions of some specific populations, such as miners and soldiers $[27,28]$. Those infected may be asymptomatic, while others may experience burning, stinging, or itching. In addition, the skin may become scaled, fissured, inflamed and/or painful [29].

In the current study, we evaluated the effect of using copper oxide impregnated socks on the well-being and appearance of the foot skin by analyzing the responses obtained from 3,585 individuals who used the socks and participated in an internet feedback survey.

\section{Methods}

\section{Screening}

Via BzzAgent (www.bzzagent.com), a screener survey was sent to identify people who have experienced tinea pedis within the past 6 months and/or were concerned about the appearance of their feet enough to actively do something to improve the appearance of their feet. BzzAgent runs word-of-mouth networks in North America and Europe, enlisting unpaid volunteers to try products from companies and then share their opinions about those products with others, inperson and online. The first 2,500 men and the first 2,500 women that responded positively were included in the study. 
Citation: Borkow G, Kanmukhla V, Monk AB (2017) Improvement to Foot and Skin Appearance by Using Copper Oxide Impregnated Socks - A Report of a Large Scale Internet Based User Survey. J Cosmo Trichol 3: 116. doi:10.4172/2471-9323.1000116

Page 2 of 4

\section{Socks}

Each of the 5,000 individuals included in the study received 3 pairs of the Copper Sole socks (also known as Cupron's PRO Therapy System (PTS) socks). The socks (Figure 1) were composed of $88 \%$ polyester, $11 \%$ nylon and $1 \%$ lycra, with the Cupron polyester being present only in the foot area of the sock at a composition of $75 \%$ polyester staple yarn and $25 \%$ nylon staple yarn. The copper oxide load per polyester staple yarn was $2.6 \%$ weight $/$ weight $(\mathrm{w} / \mathrm{w})$, thus at the active area the copper oxide load was $1.95 \%(2.6 \% \times 0.75=1.95 \%) \mathrm{w} / \mathrm{w}$.

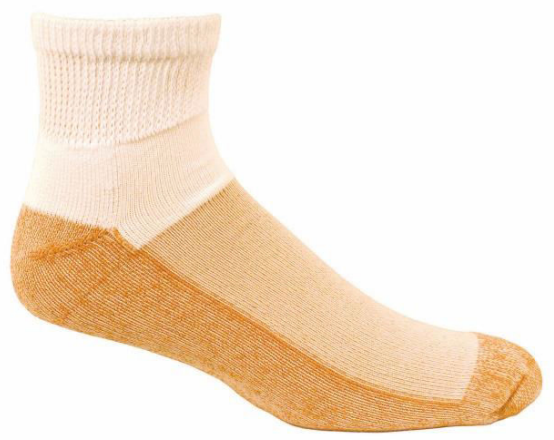

Figure 1: A representative picture of the copper sole socks supplied to the study participants.

\section{Procedure}

The volunteer participants were asked to use and wash their socks on a regular basis as they would use their regular socks. The participants were asked to fill the questionnaire detailed in Appendix A.

\section{Appendix A - questionnaire}

Question 1: On average, how often did you wear your Copper Sole socks during the campaign?

1. 5 or more hours a day

2. 1-4 hours a day

3. A few hours a week

4. Less than a few hours a week

5. Not at all

Question 2: Have you reduced or stopped another foot care remedy or routine because of the Copper Sole socks?

1. Yes

2. No

Question 3: Which of the following remedies/routines have the Copper Sole socks reduced/replaced for you? (check all that apply)

1. Lotion/Creams/Ointments

2. Sprays/Foot powders

3. Pedicures

4. Treatments at a doctor's office

5. Specially designed socks that help treat foot issues

\section{Other}

Question 4: What effect did the Copper Sole socks have on your feet? (check all that apply) (required)

1. Improved the appearance

2. Eliminated or reduced Athlete's Foot

3. Eliminated or reduced foot odor

4. Eliminated or reduced a toenail fungus

5. Reduced aches or pain

6. Kept feet dry

7. Other

8. None of these

Question 5: Are you more comfortable showing your feet in public after wearing Copper Sole socks?

1. Yes

2. No

3. I did not have a problem showing my bare feet in public before the campaign

\section{Results}

Out of the 5,000 individuals that received the socks, 3,603 answered the survey within 90 days from receiving the socks. The vast majority of the participants (82\%) used the socks at least 5 hours a day (Figure $2)$. Eighteen participants $(\sim 0.5 \%)$ answered that they eventually did not use the socks at all, and thus they were excluded from further analyses.

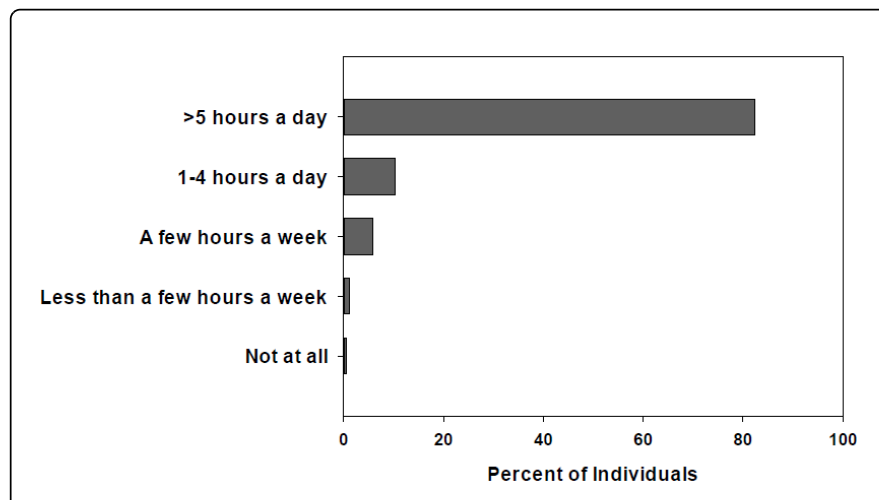

Figure 2: The frequency of usage of the Copper Sole Socks by the participants that responded to the survey.

$68 \%$ of the analyzed participants (2,429 participants) reported that they had a problem showing their bare feet in public before the campaign. Out of these 2,429 participants, 2,001 (82\%) reported that after using the socks they felt more comfortable showing their feet in public. In addition, following the use of the test socks, 2,167 participants (60\%), out of the 3,585 that were included in the analyses, reported that they stopped using foot remedies. From these 2,167 participants, $61 \%$ reported stopping using foot lotions, creams or ointments; $63 \%$ reported stopping the use of sprays and/or foot powders; $11 \%$ reported stopping pedicures; $9 \%$ reported stopping treatments at the doctor's office; $12 \%$ stopped using other socks specially designed to help treat foot issues; and $2 \%$ reported stopping using other remedies/routines. Table 1 shows the responses obtained to the question "what effect did the Copper Sole socks have on your feet?" 
Page 3 of 4

\begin{tabular}{|l|l|l|}
\hline \multirow{2}{*}{ Effect } & \multicolumn{2}{|l|}{ Responses of Participants } \\
\cline { 2 - 3 } & Number & Percent \\
\hline Kept feet dry & 2280 & 64 \\
\hline Eliminated or reduced foot odor & 2176 & 61 \\
\hline Improved the appearance & 1843 & 51 \\
\hline Reduced aches or pain & 1409 & 39 \\
\hline $\begin{array}{l}\text { Eliminated or reduced Athlete's } \\
\text { Foot }\end{array}$ & 1348 & 38 \\
\hline $\begin{array}{l}\text { Eliminated or reduced a toenail } \\
\text { fungus }\end{array}$ & 597 & 17 \\
\hline None of these & 243 & 7 \\
\hline Other & 139 & 4 \\
\hline
\end{tabular}

\section{References}

1. Uauy R, Olivares M, Gonzalez M (1998) Essentiality of copper in humans. Am J Clin Nutr 67: 952S-959S.

2. Fogelgren B, Polgar N, Szauter KM, Ujfaludi Z, Laczko R, et al. (2005) Cellular fibronectin binds to lysyl oxidase with high affinity and is critical for its proteolytic activation. J Biol Chem 280: 24690-24697.

3. Rucker RB, Kosonen T, Clegg MS, Mitchell AE, Rucker BR, et al. (1998) Copper, lysyl oxidase, and extracellular matrix protein cross-linking. Am J Clin Nutr 67: 996S-1002S.

4. Szauter KM, Cao T, Boyd CD, Csiszar K (2005) Lysyl oxidase in development, aging and pathologies of the skin. Pathol Biol (Paris) 53: 448-456.

5. Ahmed Z, Idowu BD, Brown RA (1999) Stabilization of fibronectin mats with micromolar concentrations of copper. Biomaterials 20: 201-209.

6. Ahmed Z, Briden A, Hall S, Brown RA (2004) Stabilisation of cables of fibronectin with micromolar concentrations of copper: in vitro cell substrate properties. Biomaterials 25: 803-812.

7. Sajithlal GB, Chithra P, Chandrakasan G (1999) An in vitro study on the role of metal catalyzed oxidation in glycation and crosslinking of collagen. Mol Cell Biochem 194: 257-263.

Table 1: Responses obtained to the question "what effect did the Copper Sole socks have on your feet?"

\section{Discussion}

It is estimated that more than $15 \%$ of the population suffers from foot fungal infections, mostly caused by dermatophytes [30,31]. These infections reduce the integrity of the skin, may result in secondary bacterial infections, inflammation, redness, itching and even pain [32]. These infections also have a cosmetic effect, as the skin is usually dry, may have fissures, scales and cracks, and look unhealthy, causing those suffering from these infections to be concerned of the appearance of their foot. Foot fungal infection often goes unnoticed, sometimes mistaken for dry skin [29].

The impregnation of copper oxide particles in socks takes advantage of both properties of copper, i.e. its potent biocidal properties including against fungi and its beneficial effect on the skin. Copper oxide impregnated socks have been shown to be effective in help treating acute and chronic athlete's foot infections [32-34]. In addition, a double blind, placebo-controlled study demonstrated that wearing socks impregnated with copper oxide particles increases skin elasticity [35]. Increased skin elasticity is important especially in diabetic individuals, as their skin is less elastic and very dry, increasing significantly the susceptible of their skin to infection and breakdown [29]. We hypothesized that the copper ions liberated from the copper oxide particles impregnated in the socks, by reducing the risk of fungal and bacterial infection of the foot and increasing the skin elasticity, may help protect the feet of diabetics from skin complications [36].

This study did not monitor for the medical condition of the study participants, other than including those who indicated that they have experienced tinea pedis within the past 6 months or that were concerned with the appearance of their feet. This study also did not take into consideration other factors that may have affected the participant's responses, such as their economic or education status. However, taken together, the current study indicates that the use of copper oxide impregnated socks may be also beneficial to the wider population who may be suffering from fungal infections and/or may be concerned with the cosmetic appearance of their feet.

8. Tenaud I, Sainte-Marie I, Jumbou O, Litoux P, Dreno B (1999) In vitro modulation of keratinocyte wound healing integrins by zinc, copper and manganese. Br J Dermatol 140: 26-34.

9. Kobayashi T, Saito N, Takemori N, Iizuka S, Suzuki K, et al. (1993) Ultrastructural localization of superoxide dismutase in human skin. Acta Derm Venereol 73: 41-45.

10. Gorter RW, Butorac M, Cobian EP (2004) Examination of the cutaneous absorption of copper after the use of copper-containing ointments. Am J Ther 11: 453-458.

11. Hostynek JJ, Dreher F, Maibach HI (2006) Human stratum corneum penetration by copper: in vivo study after occlusive and semi-occlusive application of the metal as powder. Food Chem Toxicol 44: 1539-1543.

12. Borkow G, Gabbay J (2005) Copper as a biocidal tool. Curr Med Chem 12: 2163-2175.

13. Borkow G (2012) Using copper to fight microorganisms. Curr Chem Biol 6: 93-103.

14. Dollwet HHA, Sorenson JRJ (1985) Historic uses of copper compounds in medicine. Trace Elements in Medicine 2: 80-87.

15. La Torre A, Talocci S, Spera G, Valori R (2008) Control of downy mildew on grapes in organic viticulture. Commun Agric Appl Biol Sci 73: 169-178.

16. Cooney JJ, Tang RJ (1999) Quantifying effects of antifouling paints on microbial biofilm formation. Methods Enzymol 310: 637-644.

17. Cooney TE (1995) Bactericidal activity of copper and noncopper paints. Infect Control Hosp Epidemiol 16: 444-450.

18. UK Marine Sack Project (2008) Copper-based antifouling paints.

19. Schultz TP, Nicholas DD, Preston AF (2007) A brief review of the past, present and future of wood preservation. Pest Manag Sci 63: 784-788.

20. Wildemeersch D, Pett A, Jandi S, Hasskamp T, Rowe P, et al. (2013) Precision intrauterine contraception may significantly increase continuation of use: a review of long-term clinical experience with frameless copper-releasing intrauterine contraception devices. Int J Womens Health 5: 215-225.

21. Borkow G, Gabbay J (2004) Putting copper into action: copperimpregnated products with potent biocidal activities. FASEB J 18: 1728-1730.

22. Gabbay J, Mishal J, Magen E, Zatcoff RC, Shemer-Avni Y, et al. (2006) Copper oxide impregnated textiles with potent biocidal activities. Journal of Industrial Textiles 35: 323-335.

23. Borkow G, Okon-Levy N, Gabbay J (2010) Copper oxide impregnated wound dressings: biocidal and safety studies. Wounds 22: 310-310.

24. Borkow G, Zhou SS, Page T, Gabbay J (2010) A novel anti-influenza copper oxide containing respiratory face mask. PLoS One 5: e11295. 
Citation: Borkow G, Kanmukhla V, Monk AB (2017) Improvement to Foot and Skin Appearance by Using Copper Oxide Impregnated Socks - A Report of a Large Scale Internet Based User Survey. J Cosmo Trichol 3: 116. doi:10.4172/2471-9323.1000116

Page 4 of 4

25. Lazary A, Weinberg I, Vatine JJ, Jefidoff A, Bardenstein R, et al. (2014) Reduction of healthcare-associated infections in a long-term care brain injury ward by replacing regular linens with biocidal copper oxide impregnated linens. Int J Infect Dis 24: 23-29.

26. Borkow G (2014) Using copper to improve the well-being of the skin Curr Chem Biol 8: 89-102.

27. Baek JH, Yoo MA, Koh JS, Borkow G (2012) Reduction of facial wrinkles depth by sleeping on copper oxide-containing pillowcases: a double blind, placebo controlled, parallel, randomized clinical study. J Cosmet Dermatol 11: 193-200.

28. Borkow G, Gabbay J, Lyakhovitsky A, Huszar M (2009) Improvement of facial skin characteristics using copper oxide containing pillowcases: a double-blind, placebo-controlled, parallel, randomized study. Int J Cosmet Sci 31: 437-443.

29. Borkow G, Elías AC (2016) Facial skin lifting and brightening following sleep on copper oxide containing pillowcases. Cosmetics 3: 24 .

30. Seebacher C, Bouchara JP, Mignon B (2008) Updates on the epidemiology of dermatophyte infections. Mycopathologia 166: 335-352.

31. Cohen AD, Wolak A, Alkan M, Shalev R, Vardy DA (2005) Prevalence and risk factors for tinea pedis in Israeli soldiers. Int J Dermatol 44: 1002-1005.
32. Bristow I, Mak M (2009) Fungal foot infection: the hidden enemy? Wounds UK 5: 72-78.

33. Ameen M (2010) Epidemiology of superficial fungal infections. Clin Dermatol 28: 197-201.

34. Achterman RR, White TC (2012) A foot in the door for dermatophyte research. PLoS Pathog 8: e1002564.

35. Borkow G, Mellibovsky JC (2012) Resolution of skin maladies of the trapped Chilean miners: the unplanned underground copperimpregnated antifungal socks "trial". Arch Dermatol 148: 134-136.

36. Borkow G (2013) Protection of Soldiers' feet by copper oxide impregnated socks. Advances in Military Technology 8: 101-108.

37. Zatcoff RC, Smith MS, Borkow G (2008) Treatment of tinea pedis with socks containing copper-oxide impregnated fibers. Foot (Edinb) 18: 136-141.

38. Dykes P (2014) Increase in skin surface elasticity in normal volunteer subjects following the use of copper oxide impregnated socks. Skin Res Technol 21: 272-277.

39. Borkow G, Zatcoff RC, Gabbay J (2009) Reducing the risk of skin pathologies in diabetics by using copper impregnated socks. Med Hypotheses 73: 883-886. 